\title{
Preventing and Reversing “Microglia-Aging” by Nature Materials for Slow Brain-Aging
}

\author{
Zhou Wu ${ }^{1 \# *}$, Aiqin Zhu ${ }^{2 \#}$, Shizheng $\mathbf{W u}^{2}$ and Hiroshi Nakanishi ${ }^{1 *}$ \\ ${ }^{1}$ Department of Aging Science and Pharmacology, Faculty of Dental Science, Kyushu University, Fukuoka 812-8582, Japan \\ ${ }^{2}$ Institution of Geriatric Qinghai Provincial Hospital, Shining 810007, China \\ \#Zhou Wu and Aiqin Zhu contributed equally to this work
}

\begin{abstract}
Mitochondrial DNA (mtDNA), which encodes components of the mitochondria electron transfer complexes, is highly susceptible to damage produced by reactive oxygen species (ROS), due to its close proximity to ROS generated through the respiratory chain and the paucity of protective histones. Accumulation of mtDNA damages during aging result in the reduced expression of the mitochondria electron transfer complexes, especially complex I. The resultant reduced activity of complex I further increases the generation of ROS, forming a vicious cycle. During aging, the accumulation of oxidative mtDNA damages is prominently found in the brain resident microglia. Increased intracellular ROS, in turn, drives microglia to provoke excessive neuroinflammation in the aged brain through activation of nuclear factor- $\mathrm{kB}$ (NF$\kappa B)$. Hypoxia activates microglia to induce the generation of mitochondria-derived ROS and the subsequent activation of NF-KB signaling pathway to produce pro-inflammatory mediators, which impairs the cognitive functions. Propolis, a resinous substance produced by honeybees, significantly inhibits the hypoxia-induced neuroinflammatory responses by microglia. Furthermore, propolis and Ratanasampil, a traditional Tibetan medicine, improve the cognitive functions of the people who are living at high altitude. Considering that the daily exposure to hypoxia is one of risk factors for the aging-related cognitive impairments, these pharmacological approaches that prevent and reverse "microglia-aging" may become a most promising future research avenue for preventing the aging-related cognitive impairments.
\end{abstract}

Keywords: Cognitive impairments; Microglia; Oxidative mitochondrial DNA damage; Nature materials; Neuroinflammation

Abbreviations: AD: Alzheimer's Diseases; IL-1 $\beta$ : Interleukin-1 $\beta$;

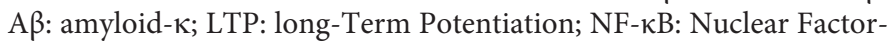
$\kappa B$; RNSP: Ratanasampil; ROS: Reactive Oxygen Species; TNF- $\alpha$ : Tumor Necrosis Factor- $\alpha$; TGF- $\beta 1$ : Transforming Growth Factor- $\beta 1$

\section{Introduction}

By the year 2030, roughly $20 \%$ of the population will be over 65 years of age in the world [1]. As the mean life expectancy continues to increase, it is an urgent issue to understand aging accelerators that are responsible for cognitive impairments associated with normal aging and Alzheimer's disease (AD). Better understanding of aging accelerators will help to invent the strategies for preventing the agerelated cognitive impairments. Microglia, the resident mononuclear phagocyte population in the brain, are activated either chronically or pathologically to influence the neuronal environment. We have provided evidence that the excessive reactive oxygen species (ROS) and pro-inflammatory mediators produced by microglia cause neuroinflammation during aging [2]. On the other hand, hypoxia can drive microglia to generate ROS [3-7], resulting in NF- $\kappa$ Bdependent excessive production of pro-inflammatory mediators, including interleukin-1 $\beta$ (IL-1 $\beta$ ), tumor necrosis factor- $\alpha$ (TNF- $\alpha$ ) and interleukin-6 (IL-6) [8-12]. Furthermore, microglia-mediated neuroinflammation is closely associated with $\mathrm{AD}$ pathogenesis [13], because overproduction of pro-inflammatory mediators by microglia triggers neuroinflammatory responses to promote neuronal damages and deposition of amyloid- $\beta(\mathrm{A} \beta)[14,15]$. On the other hand, antiinflammatory agents improve cognitive functions in $\mathrm{AD}[16,17]$. Recently, we have found that propolis, a resinous substance produced by honeybees as a defense against intruders, inhibits the hypoxia-induced production of pro-inflammatory mediators by microglia through inhibiting the generation of mitochondria-derived ROS and the subsequent activation of NF- $\mathrm{kB}$ signaling pathway [12]. Furthermore, propolis improves the cognitive functions of the people living at the high altitude [18]. On the other hand, Ratanasampil (RNSP), a traditional Tibetan medicine composing 70 nature herbal materials, improves the cognitive functions in mild-to-moderate $\mathrm{AD}$ patients living at high altitude through reducing the levels of pro-inflammatory mediators and deposition of $A \beta$ [18]. In this review, we will highlight and discuss our proposed concept of "microglia-aging", which refers to the concept that microglia are the most potent aging accelerators in the brain, in cognitive impairments associated with normal aging and $\mathrm{AD}$. We will also provide a scope that nature materials could provide significant benefits in elderly people with mild-to-moderate cognitive impairments.

\section{Microglia as Potent Aging Accelerators of The Brain: "Microglia-Aging" Concept}

There is considerable variability among individuals in the extent of decline in the cognitive functions [19]. It is noted that the cognitive functions in elderly people are severely impaired during infection [20], surgery [21] or psychological stress [22], thus indicating that brain is sensitive to systemic challenges during aging [19,23-25]. Microglia, the

*Corresponding authors: Zhou Wu, Department of Aging Science and Pharmacology, Faculty of Dental Science, Kyushu University, Fukuoka 812-8582, Japan Tel: 81-92-642-6412; Fax: 81-92-642-6415; E-mail: zhouw@dent.kyushu-u.ac.jp

Hiroshi Nakanishi, Department of Aging Science and Pharmacology, Faculty of Dental Science, Kyushu University, Fukuoka 812-8582, Japan, Tel: 81-92-6426412; Fax: 81-92-642-6415; E-mail: nakan@dent.kyushu-u.ac.jp

Received November 11, 2013; Accepted December 03, 2013; Published December 05, 2013

Citation: Wu Z, Zhu A, Wu S, Nakanishi H (2013) Preventing and Reversing "Microglia-Aging" by Nature Materials for Slow Brain-Aging. J Neurol Disord 2: 143. doi:10.4172/2329-6895.1000143

Copyright: (c) 2013 Wu Z, et al. This is an open-access article distributed under the terms of the Creative Commons Attribution License, which permits unrestricted use, distribution, and reproduction in any medium, provided the original author and source are credited. 
resident mononuclear phagocytes in the brain, is activated chronically to influence the neuronal environment during aging [2]. Perry et al. [26] first provided the concept of "primed microglia" [26-28]. Primed microglia is characterized by shortened processes and the increased expression of cell surface antigens similar to activated microglia, but they are devoid of the ability to secrete pro-inflammatory molecules. Systemic inflammatory signals activate primed microglia to provoke exaggerated neuroinflammation in comparison to normally activated non-primed microglia. The basal levels of pro-inflammatory mediators are increased during aging, leading to enhanced lipopolyssacharide (LPS)-induced sickness behavior in the aged animals. These observations suggest that microglia in the aged brain are primed and over-reacted to systemic challenges [29-33]. More recently, the mean level of IL- $1 \beta$ secreted by primary cultured microglia prepared from the aged brains is significantly higher than that from the young brains $[12,29,34]$. These observations further support our proposed concept of "microglia-aging" [2,35] (Figure 1).

The complex learning paradigms have revealed that the brain is changed structurally and functionally even in healthy middleaged individuals (over 50 years in human) [36]. The prefrontal white matter volume is significantly decreased even in the middle-age [37]. Furthermore, using adjuvant arthritic rats, an animal model of stable chronic systemic inflammatory disease, we have found that microglia induce an age-dependent differential responses to chronic systemic inflammatory challenges [38-40]. In the young adult rats, microglia produces anti-inflammatory mediators, including IL-10 and TGF- $\beta 1$, during chronic systemic inflammation. In contrast, microglia produces excessive IL- $1 \beta$, but less IL- 10 and TGF- $\beta 1$ in the middleaged rats [41-43]. These observations strongly suggest that microglia can be primed even in the middle-age and over-react to chronic systemic inflammation. Furthermore, oxidative mitochondrial DNA (mtDNA) damages are prominently found in microglia, suggesting that over production of ROS can be a cellular mechanism for priming of microglia after systemic inflammatory challenges [2,29]. The primed microglia cannot be reversed to a ground state of quiescent central housekeeping function, thus suggesting that "microglia-aging" is associated with disappearance of their abilities for maintaining homeostasis in microenvironment of the brain [2].

\section{Acceleration of "Microglia-Aging" during Hypoxia}

Brain is highly susceptible to being damaged by hypoxia because of its high demand for oxygen supply [44]. Function as the resident innate immune cells in the brain, microglia constitute the first line of defense against brain insults $[45,46]$. Hypoxia is generally accepted as the neuroinflammatogens in the brain, because hypoxia activates microglia to provoke excessive secretion of pro-inflammatory mediators, including IL-1 $\beta$, TNF- $\alpha$ and IL-6 [7-9,12]. We have previous found that excessive production of ROS due to the increased oxidative mtDNA damages in microglia is responsible for exaggerated neuroinflammatory responses in the aged animals after treatment with LPS, because the increased intracellular ROS level activates NF$\kappa \mathrm{B}$ signaling pathway which regulates the expression of several proinflammatory mediators [2]. Hypoxia can drive microglia to generate ROS [3-6], and we have recently found that hypoxia activates NF- $\kappa B$ signaling pathway to induce exaggerated inflammatory responses by microglia [12] (Figure 1).

The brain is highly vulnerable to hypoxic stress due to its high oxygen requirement and therefore, low oxygen availability at high altitudes results in cognitive impairments [47]. High altitude-induced cognitive impairments draw a special concern because this problem compromises mental performance $[48,49]$. We have previously reported that higher number of elderly people living at high altitude suffers from declines in memory and cognitive functions in comparison to that of elderly people living at the ground level [50]. A similar decline in memory arising from hypoxic exposure has been also reported in experimental animals [51]. More recent observation shows that high altitude-exposure deteriorates mainly attention, perception, judgment and working memory [52].

Stroke is the most common form of hypoxia-ischemic brain injury. In the western world, over $70 \%$ of individuals experiencing a stroke is over 65 years of age. Since life expectancy continues to grow, the absolute number of individuals with stroke will further increase in the future [53]. Activation of NF- $\mathrm{BB}$ pathway is involved in hypoxiaischemic brain injury [53-55], and microglia are clarified as the major cell population leading to NF- $\kappa \mathrm{B}$-dependent up-regulation of proinflammatory mediators, including IL- $1 \beta$ and TNF- $\alpha$ during stroke [56,57].

The chronic hypoxia contributes to the onset and progression of $\mathrm{AD}[12,58,59]$, because hypoxia activates microglia to produce pro-inflammatory mediators, including IL-1 $\beta$ TNF- $\alpha$ and IL-6 [79,12 ]. Microglia-mediated neuroinflammatory responses are closely associated with $\mathrm{AD}$ pathogenesis [13], because pro-inflammatory responses mediated by microglia promote neuronal cell damage and excessive $A \beta$ deposition $[13,60]$. It is also known that microgliamediated neuroinflammatory responses promote cognitive deficits in $\mathrm{AD}$ patients $[61,62]$. Taken together, hypoxia activates NF- $\kappa B$ signaling pathway to accelerate cognitive impairments through promoting "microglia-aging".

It is well known the close link between hippocampal functions and cognitive functions [63]. Therefore, we will discuss how "microgliaaging" impact on cognitive functions. Hippocampal long-term potentiation (LTP) is widely accepted as a cellular basis of learning and memory [64]. The exceeded expression levels of pro-inflammatory mediators in the hippocampus are associated with impairment of LTP [65-67]. In particularly, IL-1 $\beta$ potently impairs the formation of the CA1 region [68] and the dentate gyrus of the hippocampus [69,70]. Recently, we have found that the hippocampal LTP is significantly impaired in the middle-aged, but not young adult, rats during chronic systemic inflammation [71].

\section{Preventing and Reversing "Microglia-Aging" by Nature Materials}

There is increasing evidence that nature materials can provide significant benefits in dementia by their traditional usages [72]. Propolis has relevant therapeutic properties that have been used since ancient times. The chemical composition of propolis depends on the local floral at the site of collection [73-75]. In addition to the fact that propolis has anti-oxidative and anti-inflammatory effects [76-78], we recently provided the first evidence that propolis can significantly inhibit the secretion of IL- $1 \beta$, TNF- $\alpha$ and IL- 6 by microglia through inhibition of the activation of NF- $\kappa B$ signaling pathway [12]. Furthermore, propolis significantly inhibits oxidative $\mathrm{mtDNA}$ damages, which are responsible for the induction of excessive ROS and the subsequent activation of NF- $\kappa \mathrm{B}$ signaling pathway. Moreover, propolis significantly inhibits the increased expression of 8-oxo-deoxyguanosine, a biomarker for oxidative DNA damages [79], which was observed mainly in the mitochondria of cortical microglia after hypoxia. On the other hand, effects of RNSP on the oxidative mtDNA damages are to be elucidated in future studies. With the line of our previous observations that 
Citation: Wu Z, Zhu A, Wu S, Nakanishi H (2013) Preventing and Reversing "Microglia-Aging" by Nature Materials for Slow Brain-Aging. J Neurol Disord 2: 143. doi:10.4172/2329-6895.1000143

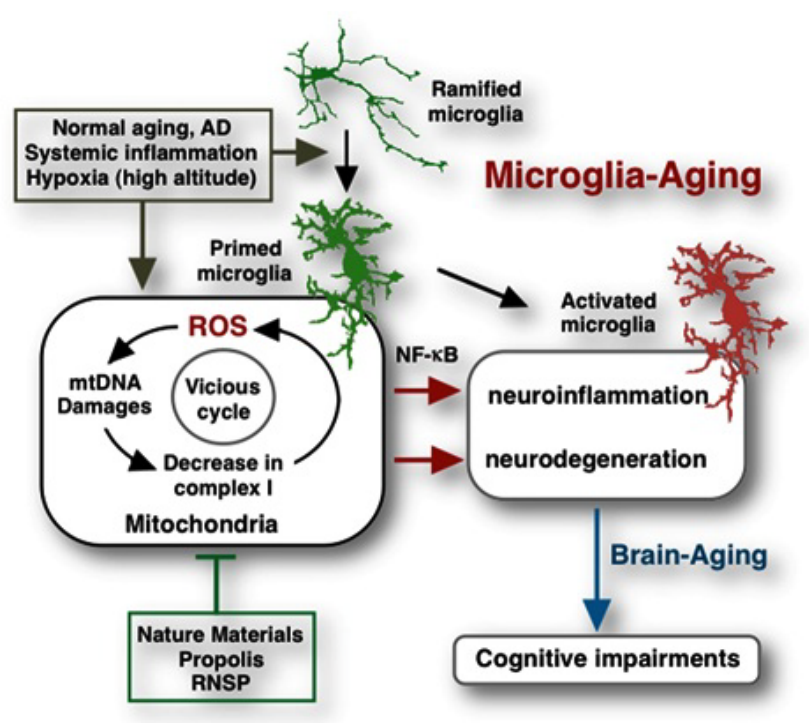

Figure 1: Schematic representation of preventing and reversing "Microglia-Aging" by propolis and RNSP. Increased microglial mitochondria-derived ROS induce neurodegeneration and neuroinflammation through activation of NF-KB signaling pathway, leading to cognitive impairments in elderly people. Increased microglial cathepsin B, a lysosomal cysteine protease, is also involved in excessive neuroinflammation during aging [35]. Nature elements, including propolis and RNSP, prevent and reverse "Microglia-Aging" to improve cognitive functions.

oxidative mtDNA damages, in turn, impair the respiratory chain, forming a vicious cycle to promote the ROS generation [2], propolis may prevent and reverse "microglia-aging" through its anti-oxidant property [76-80] (Figure 1).

People living in Qinghai-Tibet Plateau experience chronic hypoxia at high altitude. Current medical researches on the age-related cognitive impairment spay a special attention on this area, because higher number of the elderly population suffers from declines in memory and cognitive functions $[81,82]$. RNSP, one of the most important Tibetan medicines, is composed of 70 nature herbal materials [83]. RNSP is used to treat cerebrovascular diseases such as cerebral hemorrhage, cerebral infarction, epilepsy and brain concussion. Recently, clinical studies have revealed that RNSP has sedative and anti-convulsant effects, improves memory and circulation, and reduces platelet aggregation and antithrombotic properties $[84,85]$. Our previous studies have also showed that RNSP improves learning and memory in a mouse model of $\mathrm{AD}$ (Tg2576) [86,87] and improves cognitive functions in mild-tomoderate AD patients living at high altitude [18]. Furthermore, our preliminary clinical studies for people living at high altitude show that the propolis-treated elderly group obtained significantly higher scores of cognitive tests than the non-treated elderly group [18]. Moreover, both RNSP and propolis reduce the mean level of pro-inflammatory mediators, including IL- $1 \beta$, TNF- $\alpha$ and IL- 6 in the activated macrophages as well as in serum of peripheral blood of human, indicating that they also ameliorate systemic inflammatory challenges $[18,88]$. As we have discussed above, microglia can be primed even in the middle-age to sensitize to systemic inflammatory challenges. Therefore, the pharmacological approaches using nature materials that prevent and reverse "microglia-aging" may become a most promising future research avenue for improving cognitive functions of elderly people (Figure 1).

\section{Conclusion}

We provide the scope that "microglia-aging" works as a brainaging accelerator, which is associated with cognitive impairments during normal aging and AD. Propolis and RNSP, nature materials, can improve cognitive functions of elderly people through preventing and reversing "microglia-aging" (Figure 1).

\section{Acknowledgements}

This work was partly supported by Yamada Research Grant to Zhou Wu (No.0124) and Science Research Foundation for the Returned Scholars, Ministry of Human Resources and Social Security of the People's Republic of China to Aiqin Zhu (No 2012-258).

\section{References}

1. Vincent GK, Velkoff VA (2010) The Next Four Decades: The older population in the United States: 2010 to 2050. United States Department of Commerce; Washington, DC

2. Nakanishi H, Wu Z (2009) Microglia-aging: roles of microglial lysosome- and mitochondria-derived reactive oxygen species in brain aging. Behav Brain Res 201: 1-7.

3. Kaur C, Ling EA (2009) Periventricular white matter damage in the hypoxic neonatal brain: role of microglial cells. Prog Neurobiol 87: 264-280.

4. Kaur C, Sivakumar V, Yip GW, Ling EA (2009) Expression of syndecan-2 in the amoeboid microglial cells and its involvement in inflammation in the hypoxic developing brain. Glia 57: 336-349.

5. Rathnasamy G, Ling EA, Kaur C (2011) Iron and iron regulatory proteins in amoeboid microglial cells are linked to oligodendrocyte death in hypoxic neonatal rat periventricular white matter through production of proinflammatory cytokines and reactive oxygen/nitrogen species. J Neurosci 31: 17982-17995.

6. Yao L, Kan EM, Lu J, Hao A, Dheen ST, et al. (2013) Toll-like receptor 4 mediates microglial activation and production of inflammatory mediators in neonatal rat brain following hypoxia: role of TLR4 in hypoxic microglia. $J$ Neuroinflammation 10: 23.

7. Kaur C, Sivakumar V, Zou Z, Ling EA (2012) Microglia-derived proinflammatory cytokines tumor necrosis factor-alpha and interleukin-1beta induce Purkinje neuronal apoptosis via their receptors in hypoxic neonatal rat brain. Brain Struct Funct.

8. Fabbri F, Carloni S, Brigliadori G, Zoli W, Lapalombella R, et al. (2006) Sequential events of apoptosis involving docetaxel, a microtubule-interfering agent: a cytometric study. BMC Cell Biol 7: 6.

9. Carloni S, Mazzoni E, Cimino M, De Simoni MG, Perego C, et al. (2006) Simvastatin reduces caspase- 3 activation and inflammatory markers induced by hypoxia-ischemia in the newborn rat. Neurobiol Dis 21: 119-126.

10. Deng Y, Lu J, Sivakumar V, Ling EA, Kaur C (2008) Amoeboid microglia in 
Citation: Wu Z, Zhu A, Wu S, Nakanishi H (2013) Preventing and Reversing "Microglia-Aging" by Nature Materials for Slow Brain-Aging. J Neurol Disord 2: 143. doi:10.4172/2329-6895.1000143

the periventricular white matter induces oligodendrocyte damage through expression of proinflammatory cytokines via MAP kinase signaling pathway in hypoxic neonatal rats. Brain Pathol 18: 387-400.

11. Sivakumar V, Foulds WS, Luu CD, Ling EA, Kaur C (2011) Retinal ganglion cell death is induced by microglia derived pro-inflammatory cytokines in the hypoxic neonatal retina. J Pathol 224: 245-260.

12. Wu Z, Zhu A, Takayama F, Okada R, Liu Y, et al. (2013) Brazilian green propolis suppresses the hypoxia-induced neuroinflammatory responses by inhibiting NF-10º activation in microglia. Oxid Med Cell Longev 2013: 906726.

13. McGeer EG, McGeer PL (2003) Inflammatory processes in Alzheimer's disease. Prog Neuropsychopharmacol Biol Psychiatry 27: 741-749.

14. Yamamoto M, Kiyota T, Horiba M, Buescher JL, Walsh SM, et al. (2007) Interferon-gamma and tumor necrosis factor-alpha regulate amyloid-beta plaque deposition and beta-secretase expression in Swedish mutant APP transgenic mice. Am J Pathol 170: 680-692.

15. Liao YF, Wang BJ, Cheng HT, Kuo LH, Wolfe MS (2004) Tumor necrosis factoralpha, interleukin-1beta, and interferon-gamma stimulate gamma-secretasemediated cleavage of amyloid precursor protein through a JNK-dependent MAPK pathway. J Biol Chem 279: 49523-49532.

16. ADAPT Research Group, Meinert CL, McCaffrey LD, Breitner JC (2009) Alzheimer's Disease Anti-inflammatory Prevention Trial: design, methods, and baseline results. Alzheimers Dement 5: 93-104.

17. Lukiw WJ, Bazan NG (2000) Neuroinflammatory signaling upregulation in Alzheimer's disease. Neurochem Res 25: 1173-1184.

18. Zhu A, Xi A Q, Li G, Li Y, Liao B, et al. (2012) Ratanasampil (Tibetan Medicine RNSP) Reduces $\beta$-Amyloid Protein ( $A \beta$ ) and Pro-Inflammatory Factor Levels and Improves Cognitive Functions in Mild-to-Moderate Alzheimer's Disease (AD) Patients Living at High Altitude. J Behav Brain Sci 2: 82-91.

19. Laursen $P$ (1997) The impact of aging on cognitive functions. An 11 year followup study of four age cohorts. Acta Neurol Scand Suppl 172: 7-86.

20. Wofford JL, Loehr LR, Schwartz E (1996) Acute cognitive impairment in elderly ED patients: etiologies and outcomes. Am J Emerg Med 14: 649-653.

21. Bekker AY, Weeks EJ (2003) Cognitive function after anaesthesia in the elderly. Best Pract Res Clin Anaesthesiol 17: 259-272.

22. VonDras DD, Powless MR, Olson AK, Wheeler D, Snudden AL (2005) Differential effects of everyday stress on the episodic memory test performances of young, mid-life, and older adults. Aging Ment Health 9: 60-70.

23. Tsolaki M, Drevelegas A, Karachristianou S, Kapinas K, Divanoglou D, et al. (1994) Correlation of dementia, neuropsychological and MRI findings in multiple sclerosis. Dementia 5: 48-52.

24. Unverzagt FW, Gao S, Baiyewu O, Ogunniyi AO, Gureje O, et al. (2001) Prevalence of cognitive impairment: data from the Indianapolis Study of Health and Aging. Neurology 57: 1655-1662.

25. Foster TC (2006) Biological markers of age-related memory deficits: treatment of senescent physiology. CNS Drugs 20: 153-166.

26. Perry VH, Newman TA, Cunningham C (2003) The impact of systemic infection on the progression of neurodegenerative disease. Nat Rev Neurosci 4: 103-112.

27. Perry VH (2004) The influence of systemic inflammation on inflammation in the brain: implications for chronic neurodegenerative disease. Brain Behav Immun 18: 407-413.

28. Perry VH, Cunningham C, Holmes C (2007) Systemic infections and inflammation affect chronic neurodegeneration. Nat Rev Immunol 7: 161-167.

29. Nakanishi H, Hayashi Y, Wu Z (2011) The role of microglial mtDNA damage in age-dependent prolonged LPS-induced sickness behavior. Neuron Glia Biol 7: 17-23.

30. Dantzer R, O'Connor JC, Freund GG, Johnson RW, Kelley KW (2008) From inflammation to sickness and depression: when the immune system subjugates the brain. Nat Rev Neurosci 9: 46-56.

31. Dilger RN, Johnson RW (2008) Aging, microglial cell priming, and the discordan central inflammatory response to signals from the peripheral immune system. J Leukoc Biol 84: 932-939.

32. Godbout JP, Chen J, Abraham J, Richwine AF, Berg BM, et al. (2005) Exaggerated neuroinflammation and sickness behavior in aged mice following activation of the peripheral innate immune system. FASEB J 19: 1329-1331.
33. Sparkman NL, Johnson RW (2008) Neuroinflammation associated with aging sensitizes the brain to the effects of infection or stress. Neuroimmunomodulation 15: $323-330$.

34. Sierra A, Gottfried-Blackmore AC, McEwen BS, Bulloch K (2007) Microglia derived from aging mice exhibit an altered inflammatory profile. Glia 55: 412424

35. Wu Z, Sun L, Hashioka S, Yu S, Schwab C, et al. (2013) Differential pathways for interleukin- $1 \hat{\mid}^{2}$ production activated by chromogranin $A$ and amyloid $\hat{i}^{2}$ in microglia. Neurobiol Aging 34: 2715-2725.

36. Lindenberger U, Marsiske M, Baltes PB (2000) Memorizing while walking: increase in dual-task costs from young adulthood to old age. Psychol Aging 15: 417-436.

37. Salat DH, Tuch DS, Hevelone ND, Fischl B, Corkin S, et al. (2005) Age-related changes in prefrontal white matter measured by diffusion tensor imaging. Ann N Y Acad Sci 1064: 37-49.

38. Wu Z, Nagata K, lijima T (2000) Immunohistochemical study of NGF and its receptors in the synovial membrane of the ankle joint of adjuvant-induced arthritic rats. Histochem Cell Biol 114: 453-459.

39. Wu Z, Nagata K, lijima T (2002) Involvement of sensory nerves and immune cells in osteophyte formation in the ankle joint of adjuvant arthritic rats. Histochem Cell Biol 118: 213-220.

40. Wu Z, Toh K, Nagata K, Kukita T, lijima T (2004) Effect of the resection of the sciatic nerve on the Th1/Th2 balance in the synovia of the ankle joint of adjuvant arthritic rats. Histochem Cell Biol 121: 141-147.

41. Wu Z, Zhang J, Nakanishi $\mathrm{H}$ (2005) Leptomeningeal cells activate microglia and astrocytes to induce IL-10 production by releasing pro-inflammatory cytokines during systemic inflammation. J Neuroimmunol 167: 90-98.

42. Wu Z, Hayashi Y, Zhang J, Nakanishi H (2007) Involvement of prostaglandin E2 released from leptomeningeal cells in increased expression of transforming growth factor-beta in glial cells and cortical neurons during systemic inflammation. J Neurosci Res 85: 184-192.

43. Wu Z, Tokuda Y, Zhang XW, Nakanishi H (2008) Age-dependent responses of glial cells and leptomeninges during systemic inflammation. Neurobiol Dis 32: $543-551$

44. Carlson BW, Carlson JR, Neelon VJ, Hartman M (2008) Tailoring protocols to successfully recruit and retain older adults in a longitudinal study of sleep and cognition. Res Gerontol Nurs 1: 232-237.

45. Kreutzberg GW (1996) Microglia: a sensor for pathological events in the CNS Trends Neurosci 19: 312-318.

46. Streit WJ, Conde JR, Fendrick SE, Flanary BE, Mariani CL (2005) Role of microglia in the central nervous system's immune response. Neurol Res 27 685-691.

47. Adams JH (1975) Hypoxic brain damage. Br J Anaesth 47: 121-129.

48. Kramer AF, Coyne JT, Strayer DL (1993) Cognitive function at high altitude. Hum Factors 35: 329-344.

49. Lieberman P, Protopapas A, Reed E, Youngs JW, Kanki BG (1994) Cognitive defects at altitude. Nature 372: 325

50. Zhu AQ, Song CY, Yang LX, Li GF, Liao BX (2002) EEG and CT changes in Alzheimer's patients living at high altitude. Clinical Focus 17: 1313-1314.

51. Chleide E, Bruhwyler J, Mercier M (1991) Effect of chronic hypoxic treatment on the retention of fixed-interval responding. Physiol Behav 49: 465-470.

52. Wilson MH, Newman S, Imray CH (2009) The cerebral effects of ascent to high altitudes. Lancet Neurol 8: 175-191.

53. Lakhan SE, Kirchgessner A, Hofer M (2009) Inflammatory mechanisms in ischemic stroke: therapeutic approaches. J Transl Med 7: 97.

54. Nurmi A, Lindsberg PJ, Koistinaho M, Zhang W, Juettler E, et al. (2004) Nuclea factor-kappaB contributes to infarction after permanent focal ischemia. Stroke 35: 987-991.

55. Qin ZH, Tao LY, Chen X (2007) Dual roles of NF-kappaB in cell survival and implications of NF-kappaB inhibitors in neuroprotective therapy. Acta Pharmacol Sin 28: 1859-1872.

56. Gerhard A, Neumaier B, Elitok E, Glatting G, Ries V, et al. (2000) In vivo 
Citation: Wu Z, Zhu A, Wu S, Nakanishi H (2013) Preventing and Reversing "Microglia-Aging" by Nature Materials for Slow Brain-Aging. J Neurol Disord 2: 143. doi:10.4172/2329-6895.1000143

imaging of activated microglia using [11C]PK11195 and positron emission tomography in patients after ischemic stroke. Neuroreport 11: 2957-2960.

57. Price CJ, Wang D, Menon DK, Guadagno JV, Cleij M, et al. (2006) Intrinsic activated microglia map to the peri-infarct zone in the subacute phase of ischemic stroke. Stroke 37: 1749-1753.

58. Peers C, Dallas ML, Boycott HE, Scragg JL, Pearson HA, et al. (2009) Hypoxia and neurodegeneration. Ann N Y Acad Sci 1177: 169-177.

59. Gao L, Tian S, Gao H, Xu Y (2013) Hypoxia increases $A \hat{l}^{2}$-induced tau phosphorylation by calpain and promotes behavioral consequences in $A D$ transgenic mice. J Mol Neurosci 51: 138-147.

60. Ruan L, Kang Z, Pei G, Le Y (2009) Amyloid deposition and inflammation in APPswe/PS1dE9 mouse model of Alzheimer's disease. Curr Alzheimer Res 6: 531-540.

61. Okello A, Edison P, Archer HA, Turkheimer FE, Kennedy J, et al. (2009) Microglial activation and amyloid deposition in mild cognitive impairment: a PET study. Neurology 72: 56-62.

62. Lindberg C, Chromek M, Ahrengart L, Brauner A, Schultzberg M, et al. (2005) Soluble interleukin-1 receptor type II, IL-18 and caspase-1 in mild cognitive impairment and severe Alzheimer's disease. Neurochem Int 46: 551-557.

63. Sweatt JD (2004) Hippocampal function in cognition. Psychopharmacology (Berl) 174: 99-110

64. Pang PT, Lu B (2004) Regulation of late-phase LTP and long-term memory in normal and aging hippocampus: role of secreted proteins tPA and BDNF. Ageing Res Rev 3: 407-430.

65. Vereker E, O'Donnell E, Lynch MA (2000) The inhibitory effect of interleukin1 beta on long-term potentiation is coupled with increased activity of stressactivated protein kinases. J Neurosci 20: 6811-6819.

66. Cumiskey D, Curran BP, Herron CE, O'Connor JJ (2007) A role for inflammatory mediators in the IL-18 mediated attenuation of LTP in the rat dentate gyrus. Neuropharmacology 52: 1616-1623.

67. Curran BP, O'Connor JJ (2003) The inhibition of long-term potentiation in the rat dentate gyrus by pro-inflammatory cytokines is attenuated in the presence of nicotine. Neurosci Lett 344: 103-106.

68. Bellinger FP, Madamba S, Siggins GR (1993) Interleukin 1 beta inhibits synaptic strength and long-term potentiation in the rat CA1 hippocampus. Brain Res 628: 227-234.

69. Coogan A, O'Connor JJ (1997) Inhibition of NMDA receptor-mediated synaptic transmission in the rat dentate gyrus in vitro by IL-1 beta. Neuroreport 8: 2107 2110.

70. Coogan AN, O'Connor JJ (1999) Interleukin-1beta inhibits a tetraethylammonium-induced synaptic potentiation in the rat dentate gyrus in vitro. Eur J Pharmacol 374: 197-206.

71. Liu X, Wu Z, Hayashi Y, Nakanishi H (2012) Age-dependent neuroinflammatory responses and deficits in long-term potentiation in the hippocampus during systemic inflammation. Neuroscience 216: 133-142.

72. Perry E, Howes MJ (2011) Medicinal plants and dementia therapy: herbal hopes for brain aging? CNS Neurosci Ther 17: 683-698.

73. Bankova VS, de Castro SL, Marucci MC (2000) Propolis: Recent advances in chemistry and plant origin. Apidologie $31: 3-15$

74. Marcucci MC (1995) Propolis: Chemical composition, biological properties and therapeutic activity Apidologie 26: 83-99.
75. Burdock GA (1998) Review of the biological properties and toxicity of bee propolis (propolis). Food Chem Toxicol 36: 347-363.

76. Banskota AH, Tezuka Y, Kadota S (2001) Recent progress in pharmacological research of propolis. Phytother Res 15: 561-571.

77. Sforcin JM (2007) Propolis and the immune system: a review. J Ethnopharmacol 113: $1-14$

78. Ramos AFN, Miranda JL (2007) Propolis: A review of its anti-inflammatory and healing actions. J Venom Anim Toxins incl Trop Dis 13: 697-710.

79. Englander EW, Hu Z, Sharma A, Lee HM, Wu ZH, et al. (2002) Rat MYH, a glycosylase for repair of oxidatively damaged DNA, has brain-specific isoforms that localize to neuronal mitochondria. J Neurochem 83: 1471-1480.

80. Sforcin JM, Bankova V (2011) Propolis: is there a potential for the development of new drugs? J Ethnopharmacol 133: 253-260.

81. Yang LX, Chu YD, Zhu AQ (2001) Sex hormone and blood lipid changes in the female Alzheimer's patients living at high altitude. Chinese J Gerontol 12 459-460.

82. Gudmundsson G, Gudbjartsson T (2009) [High altitude sickness - review] Laeknabladid 95: 441-447.

83. Wu QX, Ji L, Ku JL, Song P (2008) [Analysis of trace elements and macro elements in 13 anti-anoxic traditional Tibetan medicine]. Guang Pu Xue $\mathrm{Yu}$ Guang Pu Fen Xi 28: 1938-1941.

84. An EJ, Suo YR (2004) Pharmacology research on Tibetan medicine Seventytaste-pearl-balls. J Medicine \& Pharmacy of Chinese Minorities 4: 33-35.

85. Bayi SHL, Hu H (2005) Research advances in Tibetan medicine Seventy-tastepearl-balls. Xinjiang J Traditional Chinese Medicine 5: 82-83

86. Zhu AQ, Chu YD, Li QX, Masters CL (2009a) Tibet-medicine effects on B-amyloid pathology in a transgenic mouse model of Alzheimer's disease. Chinese Pharmacological Bulletin 6: 720-724.

87. Zhu AQ, Masters CL, Li QX (2009b) Tibet-medicine Ratanasampil modulates 5amyloid precursor protein cleavage and C-terminal fragments (CTFS) in Tg2576 transgenic mice brain of Alzheimer's disease. Chin J Geriatr 11: 950-

88. Liu YC, Wu Z, Zhang XW, Ni JJ, Yu WX, et al. (2013) Leptomeningeal cells Transduce peripheral macrophages inflammatory signal to microglia in reponses to Porphyromonasgingivalis LPS. Mediator Inflamm.
This article was originally published in a special issue, Microglia and Synaptic Reorganization handled by Editor. Dr. Hiroshi Nakanishi, Kyushu University, Japan 